\title{
Broad Ligament Teratoma: A Rare Entity
}

\author{
Mahindra $\mathbf{R}^{* 1}$ and Neetu Kochhar ${ }^{2}$ \\ ${ }^{1}$ Associate Professor, Department of Obstetrics and gynecology, Haryana, India \\ ${ }^{2}$ Department of Obstetrics and gynecology, Haryana, India
}

Received: November 02, 2017; Published: November 15, 2017

*Corresponding author: Mahindra R, Department of Obstetrics and gynecology, BPS goverment medical college for women, sonepat, Haryana, India; Email: drvishalm@yahoo.com

\section{Introduction}

The broad ligament is a peritoneal fold that attaches the uterus, fallopian tubes, and ovaries to the pelvis. Disorders of the broad ligament are rare. Tumors of the broad ligaments are even rare. The most common solid tumor of the broad ligament is a leiomyoma. This case report is unique in world literature as first case has been documented till date.

Aim: This study was done to estimate the incidence of broad ligament tumors in our institute.

\section{Case}

A 19 year nullify porous presented in pod with abdominal mass for the last 4 months with irregular cycles .She had history of abortion 2 months back for which she underwent D\&C .Per vaginal findings revealed normal anteverted uterus with large 10 by $8 \mathrm{~cm}$ mass in right annex non tender. Her menstrual cycles were regular with 5 days flow(LMP 8 days back). On abdominal examination 14 weeks size non tender mass with variegated texture was seen in right iliac fosse. Ultrasound findings revealed left ovarian dermoid cyst. Her biochemical parameters were normal. Tumor antigen study CA125 was $<5$.She was taken for explolatory laparotomy which revealed multiloculated cystic mass arising from left broad ligament10 by 7.5 by $6 \mathrm{~cm}$ adherent to sigmoid colon, uterus and urinary bladder. Bilateral ovaries with tubes were normal. Excision of broad ligament mass was done in toot. Abdomen was closed in layers over suction drain. Postoperative period was uneventful [13].

\section{Conclusion}

Tumors of the broad ligaments are rare. Gynecologists should be aware of the possibility of retroperitoneal broad ligament teratomatous tumors.

\section{References}

1. Fernández FA, Val-Bernal F, Garijo-Ayensa F (1989) Mixed lipomas of the uterus and the broad ligament. Appl Pathol 7(1): 70-71.

2. Salman MC, Atak Z, Usubutun A, Yuce K (2010) Lipoleiomyoma of broad ligament mimicking ovarian cancer in a postmenopausal patient: Case report and literature review. J Gynecol Oncol 21(1): 62-64.

3. Bajaj P, Kumar G, Agarwal K (2000) Lipoleiomyoma of broad ligament: A case report. Indian J Pathol Microbiol 43(4): 457-458.

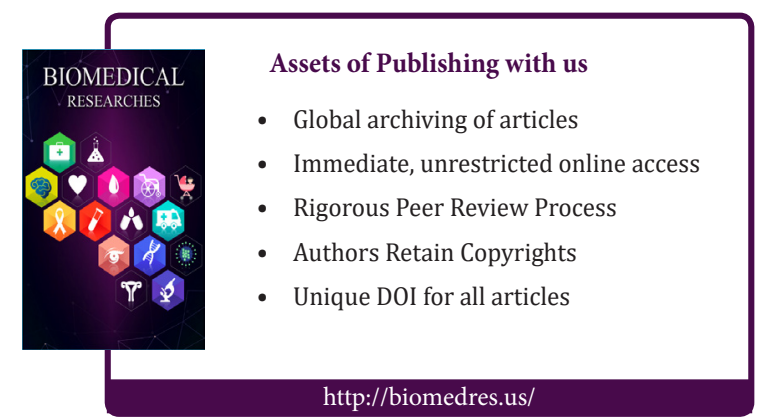

